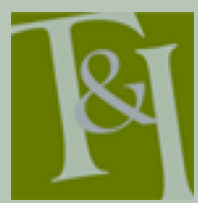

The International Journal for Translation \& In erpreting Research trans-int.org

\title{
Applications of policy and the advancement of patients' health outcomes through interpreting services: data and viewpoints from a major public healthcare provider
}

\author{
Jim Hlavac \\ Monash University, Australia \\ jim.hlavac@monash.edu

\section{Jonathan Beagley} \\ Monash University, Australia \\ jonathan.beagley@monash.edu
}

\section{Emiliano Zucchi}

Transcultural and Language Services, Northern Health; Monash University, Australia

Emiliano.Zucchi@nh.org.au

DOI: 10.12807/ti.110201.2018.a07

\begin{abstract}
This paper has policy as its starting point, relating both to society in general and to healthcare in particular. In Australia, both social and health policy coincide in their advocacy for language (interpreting) services, with the optimisation of healthcare outcomes for patients a desirable outcome of both. This paper relates these macro-level directives to the development of a hospital-wide Cultural Responsiveness Plan that represents policy guidelines at a lower level, and the way that this plan was applied and operationalised at a major public health facility, Northern Health in Melbourne, servicing up to 1 million people. Through the re-establishment of language services, a policy of transcultural training for all new and existing staff, and hospital-wide dissemination of information relating to communicating with limited English proficiency (LEP) patients, a $317 \%$ increase is recorded in the requests for interpreters at patient occasions of service (OOS) over an 8-year period. This increase is largely met by the further employment of in-house interpreters, whose cost per OOS drops in proportion to the greater efficiencies that are derived from in-house staff. The augmentation of interpreting services correlates with a $28 \%$ decrease in average LEP patient length of stay in hospital, with a decrease in the difference of re-admission rates amongst this group compared to those speaking English. This paper uses demographic data to quantify the likely percentage of LEP patients at Northern Health and matches these against the augmented level of service to show how far this is from a comprehensive or universal level of service which is usually one of the stated aims of macro- and local-level policy. Statistical data gathered longitudinally are presented alongside excerpts taken from interviews with three groups of informants: in-house interpreters, hospital managers outside language services, external language services stakeholders.
\end{abstract}

Keywords: Health policy, interpreting, patient health outcomes, public health, public policy, translation 


\section{Introduction}

Policy is a key basis for the provision of most public services and changes in policy usually bring about change - whether augmentation or contraction, or innovation or regression. Healthcare is a major public and social policy area and the focus of many stakeholders' interests. While policy is a key antecedent to service provision, it is important to track how operationalisation of policy occurs. This paper has healthcare policy and public policy relating to the accessibility of healthcare services as its starting point. Manifestations of policy such as laws, charters and guidelines which relate to the removal of linguistic barriers in healthcare are relevant as instruments that can be invoked to effect provision of interpreting services. In this paper, we identify the policy guidelines that are applied at an organisational level in the restructuring of existing services and through the establishment of an in-house entity, Transcultural and Language Services (TALS), at a large public healthcare facility in Melbourne, Northern Health (NH). 'Higher-level' policy documents can enable the establishment of 'lower-level' policy documents, such as hospital-specific frameworks that are then the 'coalface guidelines' for the implementation of policy.

As the title of this paper suggests, the advancement of patients' health outcomes is understood as a desirable result of policy guidelines. The measurement of health outcomes and the ability to attribute these, at least in part, to an augmented level of services to limited English proficiency (LEP) patients allows us to evaluate the performance of those services, in this case language services. This is important as the stated goals of most macro-level health policy guidelines do not explicitly mention linguistic diversity or interpreting services as a service area of delivery; instead, it is the need to remove communication barriers with patients so that treatment therapies can be effected that has enabled the establishment of interpreting services.

The over-arching question that this paper addresses is measurement of achievement of policy guidelines, i.e. at what point can those responsible for the provision of interpreting services know that they are close to (or far away from) providing these services to all those who require them, namely LEP patients? Policies typically advocate or require a level of service that matches their overall intentions, in this case the removal of language barriers in healthcare settings. Unless stated otherwise, policies are usually intended to be universally applied, i.e. language barriers in all healthcare settings should be removed. We follow operational processes that are in line with an overall policy for the removal of linguistic barriers (in healthcare) and track how these are able to bring about the goal of barrier-free communication between healthcare staff and LEP patients. On the basis of demographic and other data, we calculate how comprehensively interpreting services are delivered to the target group, namely all LEP patients. Further, the removal of linguistic barriers is, in itself, a means to an end to serve other purposes, namely greater efficiency and accuracy in symptom elicitation, diagnosis and treatment options for LEP patients. We examine the key metrics, length of stay (LOS) in hospital and re-admission rates, as measures of patient outcomes and relate these to the provision of interpreting services to show how an augmentation of the latter correlates with decreases in LOS and re-admission rates. Lastly, we touch on other measures such as unit-cost per interpreter-mediated OOS and the likely effects of transcultural training across the healthcare service. 
Information on $\mathrm{NH}$ patients and $\mathrm{NH}$ services are examined here at two points in time: 2007 and 2015/2016. The first year relates to 2007, before the development of the first NH Cultural Responsiveness Plan in 2010. The second relates to a point in time after the implementation of the Plan by which its effects could be measurably documented. Its implementation is outlined in Section 4 below. The same two years are used as points in time for the presentation of comparative data on the following: patient occasions of service (OOS) and those OOS that included an interpreter (Section 5.1); interpreter staffing levels, in-house vs. externally sourced interpreters and unit cost per interpreter-mediated OOS, transcultural training sessions, volume of written translation work and engagement with trainee interpreters (Section 5.2); LOS in hospital for LEP patients, LOS gap between LEP and English-speaking patients, readmission rates of patients born in a non-English-speaking country and those born in an English-speaking country (Section 5.3). Section 5.4 examines a commonly used metric in demographic descriptions - country of birth - and proposes an estimation of the proportion of those residents born in non-English-speaking countries who at the same time have limited English proficiency. The estimated number of LEP patients (or LEP residents in general) provides a statistically more precise quantification of the 'need' for interpreting services than general statistics on the number or proportion of the population born in non-English-speaking countries. Section 5.5 provides a description of how bilingual staff members, with or without an interpreting certification, may employ their linguistic skills, including inter-lingual transfer, and what relation this has to the work of in-house interpreters. Selfassessment, risk appraisal and reporting requirements for bilingual staff members that are contained in the Cultural Responsiveness Framework are a further example of policy operationalisation. Accompanying the presentation of data are excerpts from interviews conducted with three groups of informants: NH (current and past) interpreters; $\mathrm{NH}$ (current and past) middlelevel managers working outside language services; translation and interpreting (T\&I) sector stakeholders from industry and training. Inclusion of accounts from these different groups of informants allows their different perspectives to be presented alongside statistical data that thematically relate to their accounts.

\section{Policy and policy models}

Policy is a principle of action (whether implemented or not) stated by a body, usually a government authority. A definition of 'policy' from the field of Policy Studies is that it is "an officially expressed intention backed by a sanction, which can be a reward or a punishment" (Lowi \& Ginsberg, 1996, p. 607). Early research on public policy quickly came to the conclusion that policy was not an event that represented a single governmental (or other body's) decision, but a process that reflects interconnected decisions, and which almost invariably involved not one decision-maker but many (cf. Dye, 1972). Although seeming self-evident, early Policy Studies scholars such as Anderson (1984) and Bacchi (2009) make explicit the contention that public

\footnotetext{
${ }^{\mathrm{i}}$ In Victoria health services are required to develop Cultural Responsiveness Plans based on the domains, standards, measures and sub-measures set by the Department of Health \& Human Services Cultural Responsiveness Framework (Department of Health, Victorian Government, 2009).
} 
policy underscores the connection between the perception of a problem (regardless of whether that problem is real or imagined) on the one hand, and government or others' pronouncements on the other. Public policy can be conceived of as a goal-oriented activity that should include some sort of subsequent evaluation of its effectiveness (Jenkins, 1978). In other words, the study of policy should include looking at the proposal of a policy, its implementation, then a review of the policy's 'real-life' manifestation and the effects of its operationalisation. There can be lesser or greater degrees of government involvement in the formulation and carriage of policy, such as a low level that leaves policy delivery to 'voluntary' instruments such as 'private markets' or 'family and community', cf. Bischoff and Loutan's (2004) survey of 224 Swiss hospital services within which relatives were called on to interpret in $79 \%$ of instances. Or there can be a higher level of involvement in which 'compulsory instruments' are employed such as 'regulation', 'public enterprises' and 'direct provision' so that the policy has a higher degree of success through these more compelling means. In between, there can be a 'mixed level' of involvement consisting of 'information and exhortation' (e.g. public announcement campaigns), 'subsidies' (e.g. grants and sponsorships), and 'tax and user charges' (e.g. user-pay regimes as a disincentive). The Dutch government's decision to charge allophone patients for the cost of requested interpreting services in hospitals is an example of this (Hof, 2013).

In relation to public policy and healthcare Buse et al. $(2005$, p. 8) state that "health policy covers courses of action (and inaction) that affect the set of institutions, organizations, services and funding arrangements of the health care system (both public and private)". As a very large public sector, healthcare is shaped not only by policy directions, but financial (budgetary) considerations and logistic ones (available human resources, available physical infrastructure). While expressed policy is an antecedent to government services, the delivery of these services is also co-determined by other things. Descriptions of policy development are cognisant of this, with one Policy Studies model, Multiple Streams Framework, identifying "resource adequacy, technical feasibility, network integration, value acceptability", together with the importance of key protagonists, "policy entrepreneurs", and advantageous points in time, "policy windows", as other attributes that are taken into consideration in the process of policy creation (Sabatier, 2007, p. 10).

Australian health policy has undergone many changes, particularly since the post-WWII establishment of many welfare state institutions. Further changes have occurred since the mid-1970s when multiculturalism became national and cross-portfolio policy in Australia. Garrett (2009, p. 46) identifies the following general directions in healthcare policy since the mid1970s: the principle of 'equity and access' with healthcare interpreter services initially introduced as a measure to redress social disadvantage; efficiency and equity, together with de-institutionalisation and the first wave of prioritising externally contracted interpreters ahead of in-house interpreting services. At the same time, health services started to become more culturally competent leading to more frequent requests for interpreters. Increased demand for interpreter services resulted also from an ageing migrant population with attriting proficiency in English. Further to this, wage increases and increasing costs of medical technology led to an "accelerated efficiency drive" in the 1990 s that was accompanied by an almost universal casualisation and outsourcing of interpreter services, with telephone and video-link interpreting 
sometimes advocated as responses to the need for 'greater efficiency' and mounting health costs.

Writing in reference to the first decade of the new millennium, Garrett (2009, p. 46-47, original brackets) locates the following features as prominent ones in health policy documents: health outcomes, performance monitoring and patient safety, with an emphasis on the latter leading her to report that "... a disjuncture has arguably emerged between the driving policy ideals of the mainstream (patient safety) and the goals and ideals of the interpreter policy (access and equity)". It is perhaps hard to locate what characterises health policy in the period from 2010 onwards in Australia. It may be that things such as patient-centred care, patient choice and autonomy and an increased awareness of the legal consequences of medical treatment, including liability appear may be more prominent policy features of this current decade. It may be that increased concerns for patient safety and fear of litigation will lead to a reappraisal of the way healthcare services, including interpreting services are provided. The negative effects of out-sourcing and the need to minimise risk potential may 'swing the pendulum' back to in-house interpreting services. Further, the cost of external interpreting services provided by casually employed contractors may no longer represent a cost saving. This last point is looked at in section 5.2.

There are no public policies in Australia that focus specifically on interpreting services ${ }^{\text {ii }}$. Interpreting, translation or linguistic mediation (hereafter 'T\&I') are mentioned across a number of laws, guidelines and charters, but almost always as a service feature that facilitates the provision of other services, and not as a specific objective of policy delivery itself. Australian policy analysts in T\&I such as Ozolins (2010) describe the presence of T\&I as "cross-sectoral that conflict with usual sector-specific policy development" and that has "institution-led, rather than profession-led standards and practices". This means that interpreting services are largely shaped by government requirements and it is Australian federal and state governments who indirectly oversee the credentialing of interpreters in Australia, via a national certification authority, the National Accreditation Authority for Translators and Interpreters ${ }^{\text {iii }}$. The notion of an 'interpreter policy' is therefore a construct, not a sanctioned document and Garrett's 'Model of Interpreter Policy in Healthcare' conceptualises 'interpreter policy' as a notion that operates

... within a context that is both defined and influenced by the broader political and social context. Thus attitudes towards immigration, immigrants, health and welfare social provision all (explicitly or implicitly) frame, mediate and influence interpreter service policy and provision.

(Garrett, 2009, p. 45. Original brackets).

\footnotetext{
ii Public policies that specify interpreting services are usually specific to a particular area of public services, and often at a state, not national level.

iii The only policy that comes close to being an 'interpreting policy' is the National Policy on Languages (NPL) released in 1987 (See Lo Bianco, 1987), which included T\&I as one of four national areas of activity. The NPL emphasises the importance of training of interpreters and translators for all languages groups - immigrant and indigenous languages as well as Auslan. Policy vision comes through in this document through the call for T\&I to be considered not a 'stop-gap' measure for peripheral groups, but an integral part of intra-group communication, i.e. amongst all those who belong to the Australian population. By the late-1990s, the NPL was no longer an authoritative document and had been sidelined by subsequent government initiatives.
} 
In a model that posits that a number of factors determine interpreter policy in healthcare, Garrett (2009, p. 45) distinguishes management factors relating to human resources capacity and management of budget allocations as ones that can determine health interpreting policy. These and other factors are discussed below in Section 5 .

\subsection{Manifestations of policy - laws, charters, guidelines etc.}

As outlined, the provision of interpreting services in Australia is not determined by a single policy but by government or institutional factors across a range of sectors. These include not only healthcare, but the executive (police and law enforcement), the judiciary, education, trade, tourism as well as other areas. There are also policies that are not sector-specific but ideological or macro-social in their intentions, such as multiculturalism, social cohesion, diversity, anti-discrimination measures, and further ones that are demographic such as tackling ageism and preparing for an ageing society, or tackling disadvantage towards or amongst indigenous Australians. These further policies can have an effect on healthcare and on the operationalisation of services in healthcare including T\&I services.

The healthcare provider about which data are provided in this paper is Northern Health, a public healthcare provider that provides services to approx. 1 million people in Melbourne's (pop. 4.5 million) northern suburbs. Northern Health is an amalgamation of singly-functioning older hospitals and newer health facilities that has undertaken a strengthening of its interpreting services over the last 10 years as part of its overall approach to the needs of its patients in a culturally and linguistically diverse (CALD) area of Melbourne. From 2007 onwards, Northern Health's in-house interpreting services, TALS, has drawn on and invoked laws, regulations and frameworks from a variety of public policy areas to establish and extend its services:

- Healthcare - Victorian Health Services Act 1988, Australian Charter of Healthcare Rights (2008); Victorian Department of Health's Cultural Responsiveness Framework (Department of Health, Victorian Government 2009).

- Social cohesion - Growing Victoria Together to 2010 and beyond (Department of Premier and Cabinet, State Government of Victoria 2005), A Fairer Victoria. Progress and Next Steps (State Government of Victoria 2006), The Charter of Human Rights and Responsibilities Act 2006;

- Multiculturalism - Multicultural Victoria Act 2004, Victorian Education for Global and Multicultural Citizenship 2009-2013 (Department of Education and Early Childhood Development 2009), All of Us, Victoria's Multicultural Policy 2010;

- Anti-discrimination legislation - Human Rights and Equal Opportunity Act 1986, Racial and Religious Tolerance Act 2001;

The important feature to note here is that it is not health policy alone that can be invoked to achieve interpreting services within healthcare services. There can be other areas of social policy and anti-discrimination laws that can serve a similar purpose. Focusing on the first-mentioned sector healthcare that is directly influential on our discussion, the Australian Charter of Healthcare Rights (2008) is a document that has a greater influence on service provision than laws or regulations. When a patient is admitted to a public hospital in most urban areas, the need for an interpreter is one of the preliminary pieces 
of information elicited at the first point of contact. The Charter states that patients have "a right to be informed about services, treatment, options and costs in a clear and open way", with an even clearer message issued in the second person: "You can use interpreters if English is not your first language. Interpreter services are free and can be provided in person or by phone". It is hard to think of a patients' rights document that could be clearer or more forthright in its pronouncements.

A state-based document, the Australian Charter of Healthcare Rights in Victoria (Australian Commission on Safety and Quality in Healthcare (2016), pp. 9, 12. Original emphasis) is even clearer in defining patients' rights: "You have a right to an accredited interpreter if you need one when using a publicly-funded healthcare service, such as a hospital or community health centre" and "Interpreters should be provided at important points during your care, such as when discussing medical history, treatments, test results, diagnoses, during admission and assessment and when you are required to give informed consent". This kind of specification of interaction type for which an interpreter "should be provided" gives not only patients but also healthcare providers a clear direction on when an interpreter needs to be present. The wide range of interactions listed means that, in effect, an interpreter is requested for all interactions where a patient receives medical advice or treatment.

Within the field of mental health, the content of legislation in Australian states also usually has the effect that interpreting services are provided where they are needed. For example, the Victorian Mental Health Act 1986 (Part 2, Section 5B, Section 18(3)) requires this at the point of admission, and at other points where permission for treatment is requested, i.e. that the "legal rights and relevant provisions... are explained to patients and other people with a mental disorder in the language... which they are most likely to understand". Further, the act specifies that "in addition to the statement, the patient must be given an oral explanation of the information contained in the statement... in the language... which he or she is most likely to understand". The wording of this law relates to the perceptionary or cognitive capability, as well as the linguistic profile of mental health patients. This wording is widely understood and applied to the situation of LEP patients in a way that interpreters are requested for such interactions.

In general, acts, charters and frameworks mention the provision of interpreting services or the need for linguistic mediation in most cases where service delivery is considered. This also usually applies outside the healthcare sector.

\section{Data sample and methods of data collection}

This paper presents three sets of data. The first sample is a collection of comparative data from two years of TALS' operations, 2007 and 2015/2016 and includes features such as staffing levels, service request volume, coverage of these, comparative cost factors and other data relating to TALS performance. These are presented in sections 5.1 to 5.4. The second sample consists of demographic data extracted from census collections on reported language levels amongst residents located in municipalities served by Northern Health. These data are presented in section 5.4. The third sample consists of qualitative data that are the presented viewpoints of interviewed human informants. 
The human informants are from three groups identified as relevant to this examination of policy implementation: current or former employees of TALS; current or former employees in managerial positions of other entities within Northern Health who had regular contact with TALS from the time of its restructuring in 2007; stakeholders outside Northern Health (agency managers, government policy advisors, interpreter trainers) in the T\&I sector. These three groups were identified on the basis of the range of their perspectives, ranging from in-group/occupational and in-group/managerial to outgroup/managerial and out-group/occupationally-related. Nineteen potential informants from all groups were contacted to participate in the study as interviewees. Thirteen stakeholders consented to being interviewed and twelve were successfully interviewed (overall response rate: 63\%). There are four informants from each of the three groups. Interviews were structured and informants were given the chance to expand on and digress from set questions. Interviews took place from October 2015 to May 2016 ${ }^{\text {iv }}$. All informants were asked similar questions to ensure comparability across the sample. Questions asked to the three groups of informants are contained in the appendix.

All informants were de-identified. Content information that could identify them was removed. Extracts from informants are attributed according to the group that they belong to, in the following way: 1) TALS (+informant no.); NH-Manager (+informant no.); T\&I-sector (+informant no.). Thus, the designation 'NH-Manager 2' refers to a Northern Health manager, working outside TALS, informant no. 2. Excerpts from the interviews are presented not as a separate section within this paper, but provided as 'informant voices' that exemplify, augment or elucidate discussion, including the presentation and elucidation of statistics.

\section{Implementation and operationalisation of healthcare policy and interpreting services - the example of Northern Health, Melbourne}

This section provides a description of the implementation of macro-level policy documents such as guidelines or laws (discussed above in 2.1) at a lower level by an individual healthcare provider, in this case Northern Health. In Australia, it is mostly the states and territories rather than the federal government that shape healthcare policy. Discussion here focuses on the state in which NH is situated, Victoria. In 2009, a 'landmark' document in the provision of health services was the Victorian Department of Health's Cultural Responsiveness Framework. The statistical data that we present in this paper are taken from the years 2007 to 2015/2016 - these years encompass a period that started before and after the release of the 2009 Cultural Responsiveness Framework.

In 2007 only 7\% of occasions of service (OOS) featured an interpreter, despite the fact that $43 \%$ of NH's patients were born in non-English speaking (NES) countries. Across all of NH there was a low number of interpreters working in-house at the time, who covered $29 \%$ of total requested interpreter OOSs.

\footnotetext{
iv Approval to interview human informants for this project was granted by Monash University Human Research Ethics Committee on 7 September 2015. Project Number: CF15/3333 - 2015001414 Project Title: A study on the policies and implementation of language services in healthcare settings.
} 
The cost of supplying an in-house interpreter per requested OOS was high. In comparison, the sourcing of interpreter externally through a language services provider was $\$ 15$ less expensive. Certain inefficiencies in workplace duties existed such as all interpreters taking on booking duties which contributed to a low, per-day number of OOSs for in-house interpreters, usually amounting to only five.

Transcultural training for other staff across $\mathrm{NH}$ was uncommon, and the volume of translated documents/words was small, and usually not performed by in-house interpreters (but by external translators). A NH middle-level manager describes the situation before TALS's establishment in 2007.

There was no concentrated effort to use interpreter services - a lack of awareness and a lack of understanding of the need to use this service. There was also a cost involved and a reluctance to use any service for this reason. Accessing an interpreter service prior to TALS was difficult and inefficient and unreliable. There was a much higher incidence of family members interpreting and the validity of this interpretation was questioned many times. There were very few translated materials for the services offered by $\mathrm{NH}$ - hence a significant under-use, misuse and abuse of these services. (NH-Manager 1)

While NH had a low level of use of interpreters in 2007, the heavy reliance on externally contracted interpreters had other consequences. Variation existed in the capability and level of professionalism displayed by externally sourced interpreters. Randomly-collected and anecdotal evidence suggested that many lacked training with a variable knowledge of the AUSIT Code of Ethics. This lack of professionalism often confirmed popular images of interpreters as no more than lay people with proficiency in two languages. The role of interpreters was often misunderstood, and clinicians regularly relied on family members to interpret for them, as mentioned in the above quote. Complaints about interpreter performance were also widespread. Variability in interpreter performance is, in part, a result of the deregulation and casualisation of the language services industry in Australia over the last 25 years (Hlavac, 2016). A manager of a language services agency has the following to say about deregulation:

The interpreter supply in this industry is being compromised by a casualised model. [...] you asked me earlier whether the interpreting service has changed [...] the relationship of the suppliers has changed. Can you imagine if we, tomorrow, we casualised all doctors working in the public health care system? In other words, we set them all [free] and we put them out in the industry and we go to an agency which [is] called 'medical services' and every time somebody walks in the hospital and says 'I need to see a doctor' we call that agency and say 'send me a doctor, send me a GP'. Let me tell you that there will be many doctors who would probably live below the poverty line and that would move away from the industry. The public health care system needs to treat language services like it treats all other disciplines. And they should wait until the interpreter is available, like we wait until the GP becomes available. Right now, the system says, 'I need an interpreter in Punjabi at 2 o'clock tomorrow', you know, and they have an expectation that everybody, $[\ldots]$ they all want a Punjabi interpreter at the same time. So what do we do? We have 500 Punjabi interpreters and they do 1 booking a day? It's an unsustainable system in other words. (T\&I-sector stakeholder 1)

As a response to the variable skill level displayed by casually contracted interpreters, TALS considered the possibility of up-skilling and further training for in-house employed interpreters. Relevant literature was consulted, 
e.g. Angelelli (2004) and Johnstone and Kanitsaki (2007a, 2007b), and a reviewed and extended Transcultural Healthcare Policy (THP) was released in May 2008. At the same time, language services were centralised and standardised across all hospital campuses. NH developed internally an online booking system capable of interfacing with all other hospital systems. The booking system was connected to patient lists in the relevant clinics with prepopulated information already available. The process of booking an interpreter was greatly simplified with a process of no more than eight clicks required via a range of drop-down menus. The system also alerted the requestor to booking clashes across different areas for the same patient. It also gave management detailed data reports. A TALS staff member describes the augmentation of services in the following way:

TALS started offering a greater range of services. More in-house interpreter/translators were employed to keep up with changes in patient demographics. A Cultural Liaison Officer was introduced, and then a bookings officer. TALS now had the resources to effectively run training, manage a translations database, but also attend meetings, and implement the Cultural Responsiveness Plan. With the previous system this would have been very difficult to do. (TALS-Employee 2)

An outcome of the THP was also the realisation that more in-house interpreters would be needed to make interpreting more accessible and to better control the quality of interpreting. It was not known at this time if this could also be a cost-saving measure. Initial analysis indicated that it was: within 10 months, the price per interpreter per OOS had started to fall. This was contrary to the predictions of prevailing trends in national macroeconomic policy that advocated out-sourcing as a cost-saving factor. Communication with all departments of $\mathrm{NH}$ was greatly improved through the establishment of the TALS Newsletter which both explained booking procedures and how to best work with interpreters. Increased visibility is described by a middle-level manager in the following way:

TALS has given language services a higher level of prominence within the organization and a higher level of accountability to patients and consumers that it works with, and that are part of its catchment. (NH-Manager 3)

And by an interpreter in the following way:

In comparison with other places where I've worked, I've never had a sense of the presence of interpreters before. I think the promotional, the PR stuff that was done around that space and making sure that there were connections with the right stakeholders was really important. I don't often see that in a lot of health services now. And I hadn't seen that before I came to Northern. (TALSEmployee 4)

And another middle-level manager describes the augmentation of services, including the newsletter and transcultural training, as examples of the patient-centred care provided by TALS in the following way:

CALD patient-centred care is achieved by interacting with the patient and family and determining what is important to both the patient and family. This is regularly done with the assistance of the TALS group who have over the years delivered information on the various ethnic groups in their newsletter. This was an amazing resource for $\mathrm{NH}$ staff. The care needs to centre on the patient. Hence, an interaction with the patient independent of the family is very 
important. Frequently families try to protect their loved ones from bad or unwelcome news and their translation often reflects this. An interpreter is essential in this instance." (NH-Manager 4)

The centralisation of language services, a new policy (THP), an increase in the number of in-house interpreters (who also required a translation credential), the new bookings system, and communication networks characterised the first year of TALS in 2008. TALS introduced transcultural training as a compulsory component of training for new staff, and as professional development PD for existing staff. TALS initiated steps to have language services classified in a way similar to other Allied Health disciplines, with career path planning and moves to increase remuneration. By 2011/12 TALS had defined five key strategic areas for its operations:

1. Policies. Review of hospital-wide policies relating to language services and TALS; development of a Northern Health Cultural Responsiveness Plan, as a document that locally implements the Victorian Health Department's Cultural Responsiveness Framework. Alignment of TALS activities with the Australian Commission on Safety and Quality in Healthcare's national accreditation standards and requirements.

2. Staffing. Review of position descriptions and employment strategies; professional development and mandatory training; supervision and annual performance appraisal; attendance at and participation in the monthly Lost \& Found in Translation (LAFIT) Forum where issues pertaining to interpreting and translation are discussed.

3. Education and research. Creation and review of transcultural training material and education calendar for all NH staff; collaboration with other hospital departments in research projects (requiring as per policy a $25 \%$ cohort of patients with LEP); collaboration with universities to host trainee/student interpreters; staff surveys.

4. Interpreter demand. Analysis and streamlining of demand, design and application of patient surveys, analysis of macro-institutional data.

5. TALS electronic portals. Translations Database \& Waiting List, Multilingual information on Intranet and health service website.

TALS now finally had a model. This was developed on the basis of policy directions alone, with little other modelling based on arrangements at other, comparable public healthcare facilities. These themselves faced problems similar to those encountered by TALS in 2007. The following section outlines how the TALS model was applied and implemented.

\section{Data and viewpoints on the provision of interpreting services}

The focus now switches to a discussion and evaluation of the operationalisation of policy. By 2015/2016, TALS had become an entity that employed 37 in-house interpreters with language needs not covered by inhouse interpreters met by externally contracted interpreters. In 2015-2016 TALS provided interpreting services in over 100 languages. Table 1 below sets out comparative statistics from 2007 before TALS began to engage with key health policy regulations and before the development of the Northern Health Cultural Responsiveness Plan. These are contrasted with statistics that 
were collected 8.5 years later, in the period from 1 July 2015 to 30 June 2016, by which time TALS had diversified and augmented its level of service provision for patients' communicative needs.

\subsection{Occasions of service}

A key metric used in the measurement of healthcare services is 'occasion of service' (OOS) that refers to "any examination, consultation, treatment or other service provided to a patient" (Dept. of Health, Western Australia, n.d., p. 1). Table 1 below shows comparative figures from two years, 2007 and 2015/2016 for OOS and service requests for interpreters.

Table 1: Patient occasions of service (OOS) Service and the provision of interpreting services for the years 2007 and 2015/16.

\begin{tabular}{lll}
\hline & 2007 & $2015 / 16$ \\
\hline Total no. of patient occasions of service (OOS) & 233,839 & 286,647 \\
\hline No. of service requests for an interpreter & 17,000 & 53,822 \\
\hline Overall \% of interpreter-mediated OOSs & $7.3 \%$ & $18.8 \%$ \\
\hline $\begin{array}{l}\text { No. }+\% \text { of service requests that were not } \\
\text { delivered }\end{array}$ & n./a. & $1,802(3 \%)$ \\
\hline
\end{tabular}

Over the aforesaid eight-year period, there has been a $22 \%$ increase in patient occasions of service (OOS). This increase is attributable to demographic changes, the most important of which is the settlement of new residents in NH's catchment area, as well as the widening of the catchment area in 2012. The increase in service requests for interpreters has increased by $317 \%$ over the same period. This steep rise in service requests can be attributed to a number of occurrences outlined above in section 4: greater awareness of the importance of booking an interpreter (cultural training), knowledge of how to do this (simplification of booking system, dissemination of instructions on how to use it), augmentation of interpreter availability (staffing).

The number and percentage of OOS that were interpreter-mediated were 17,000 (est.) and $7.3 \%$ in 2007 , and 53,822 and $18.8 \%$ in $2015 / 2016$. There is a rate of 3.3\% inability to service requests for interpreters. This rate is low in comparison to equivalent figures available from a major interpreting agency, ONCALL Language Services in Australia that recorded 29,216 instances of 'inability to service', or $7 \%$ of its total number of 410,017 service requests for the year 2015 (Hlavac et al., forthcoming). There is a high percentage of ability to address service requests and the attainment of this high percentage needs to be seen in light of the fact that the regulative mechanisms are directed at all residents (in this case, patients), not only those who belong to particular (usually large) language groups. This means that interpreters for languages such as Finnish, Hakka, Nepali and Samoan need to be provided (often via telephone) in the same way that they are for speakers or more widely-spoken languages such as Turkish, Cantonese, Dari and Macedonian. Further, as mentioned above in Section 4, the wording of rights (cf. Australian Charter of Healthcare Rights in Victoria) that apply to patients, "You have a right to an accredited interpreter...", "Interpreters should be provided" (Australian Commission on Safety and Quality in Healthcare 2016, pp. 9, 12) leave little space for doubt as to what is incumbent on the language services provider. 
A positive correlation between augmented interpreting services and financial savings made outside language services, i.e. throughout areas of medical care in a hospital, through reduced length of stay and lower readmission rates is reported by Lindholm et al. (2012). Further cost-relevant factors that relate to interpreting are provided below in 5.2.

\subsection{Augmentation of staffing and other, non-interpreting services}

As outlined above, the deregulation and casualisation of language services occurred as a consequence of macro-economic policy that advocated outsourcing as the most cost-effective way to reduce salary and labour costs. (This occurred in many sectors of the economy, not only in language services.) An augmentation in the employment of in-house interpreters was therefore seen as a risk-laden step with unclear consequences. Table 2 below presents data on the number of TALS staff, and on the statistics and unit cost per interpreter mediated OOS.

Table 2: TALS staffing levels; frequency and cost of interpreter-mediated OOSs.

\begin{tabular}{lll}
\hline & 2007 & $2015 / 16$ \\
\hline Overall and EFT no. of in-house interpreters & 5 (EFT: 5) & $\begin{array}{l}37 \text { (EFT: 21.6 + } \\
\text { casuals) }\end{array}$ \\
\hline No. and \% of service requests for an interpreter & 17,000 (est.) & 53,822 \\
\hline Overall \% interpreter-mediated OOS & $7.3 \%$ & $18.8 \%$ \\
\hline$\%$ of in-house interpreter-mediated OOS & $2 \%($ est.) & $13 \%$ \\
\hline Ave no. of interpreter OOS per day & 5 & 8.6 \\
\hline Interpreted-mediated OOS in-house, no. + \% & $4,942(29 \%)$ & $32,155(60 \%)$ \\
\hline Interpreted-mediated OOS external, no. + \% & $12,058(71 \%)$ & $19,685(37 \%)$ \\
\hline No. of service requests that were not delivered & n./a. & $1,802(3 \%)$ \\
\hline $\begin{array}{l}\text { Unit cost per interpreter-mediated OOS: } \\
\text { in-house vs. external }\end{array}$ & $\begin{array}{l}\text { External } \$ 15.00 \\
\text { cheaper }\end{array}$ & $\begin{array}{l}\text { In-house } \$ 22.47 \\
\text { cheaper }\end{array}$ \\
\hline
\end{tabular}

Table 2 above shows an increase in the number of in-house interpreters employed by TALS. The increase from 5 to 35 is a very large increase; in terms of costs, the increase was much less than this, as most in-house staff are employed part-time and the increase in the equivalent full-time (EFT) cost is around $200 \%$, from 5 to 21.6 . The 53,822 requests for an interpreter in $2015 / 2016$ represent $18.8 \%$ of all OOSs. This is a substantial increase compared to the percentage of all OOSs that were interpreter-mediated in $2007-7.3 \%$. In that year, only $29 \%$ of interpreter requests for service could be serviced by in-house interpreters. In 2015/2016 this percentage had risen to $60 \%$. In achieving this increase in interpreter OOS, the average number of OOS completed by an in-house interpreter has risen from five OOS per day to 8.6 OOS per day. This, as well as the other increases shown here, is substantial as it relates to not only the 'coverage' that in-house interpreters provide at $\mathrm{NH}$, but also the vastly increased number of requests for service for an interpreter. A middle-level manager describes how the increase has come about:

I would think the operationalising of the attitude of staff, so putting legs on the attitude is about more bookings, so people book the interpreters when they're required. There's always going to be pockets of clinicians who think they can get away with using family members and so on and don't recognise the ethical implications of that and the safety implications of that, but I think 
operationally, it is really about whether people do bother to get interpreters when they're supposed to be getting them in. (NH-Manager 2)

In 2007 the difference in per unit cost between an in-house and an externally contracted interpreter was A\$15.00, with external interpreters cheaper. The increase in the number of in-house interpreters has led to an increase in the TALS salary budget. But through this, the unit cost for a service request provided by an in-house interpreter could be greatly reduced, and by 2015/2016 in-house interpreters were $A \$ 22.47$ cheaper per unit-cost than externally contracted interpreters. The employment of in-house interpreters was therefore a more cost-effective measure. If TALS had continued to respond to service requests with a percentage ratio of $30 \%$ provided by in-house and $70 \%$ by external interpreters, as was the case in 2007, then its labour costs budget would have been considerably greater than those from $2015 / 2016$, i.e. the augmentation of in-house interpreting services has resulted in an overall lower cost for interpreting services as a whole. Through the increased employment of interpreters, particularly multi-lingual and multi-accredited in-house ones, a substantial cost saving has been effected in language services in relation to the provision of its services.

The increase in staffing was also achieved through a strong invocation of the regulations that oblige public healthcare facilities to provide comprehensive interpreting services across a range of services. These are contained in the Australian Charter of Healthcare Rights in Victoria (cf. Section 4).

Under the 5 key strategic areas that TALS had set in 2010, two relate to staffing and education/research. Table 3 below sets out data on activities relating to these:

Table 3: Training sessions for other NH staff, translations and student placements

\begin{tabular}{lll}
\hline & 2007 & $2015 / 16$ \\
\hline Transcultural training sessions (+ staff nos.) & 35 (n./a.) & $89(1114)$ \\
\hline No. of translated documents (+ words) & $15(55,554)$ & $40(92,580)$ \\
\hline Student placements & 0 & 21
\end{tabular}

Table 3 shows that the number of transcultural training sessions had more than doubled, from 35 to 89 , with $1,114 \mathrm{NH}$ staff reached through such training. The increase in training sessions is a consequence of policies from both outside and inside TALS: the NH Cultural Responsiveness Framework required new staff to undertake transcultural training; TALS' second key strategic area lists PD for new and current NH staff as a priority. An NH manager describes how the framework has been applied in relation to interpreting services:

I think TALS [...] has been able to temper the cultural responsiveness framework, [...] kind of doing the more aspirational or extra activities, and that's good... TALS has been able to look at more innovative ways of demonstrating the need [for augmented interpreted services] as correlating to the health care delivery and potential outcomes for patients. That has been a significant contribution by TALS. (NH-Manager 3)

Compulsory transcultural training for employees new to $\mathrm{NH}$ has been achieved. The impression that other NH employees have about transcultural 
training and about language services in general is described in the following way by an in-house interpreter:

I think, quite highly is my impression. I think a lot of the medical people kind of recognised how valuable it is in, particularly in really dire and tricky situations. However, I would say that TALS was always going to be doing the consistent, kind of, battle to make sure that everyone gets educated, that the new people coming into Northern get educated and making sure that everyone knows how to use the service. And there are some people who engage with that better than others. And typically medical people are the slowest to take that kind of stuff up and are the hardest to get to go to. (TALS-Employee 2)

An increase in the number of translated documents and in the volume of translated words (or equivalents thereof) is attributable to two staffing measures: the requirement that newly employed in-house interpreters possess translator accreditation as well as an interpreting credential; and the fact that the employment of multi-lingual interpreters also greatly increased the number of languages that could be serviced by TALS' accredited translators. Further to staffing, TALS engaged actively with three interpreter training institutions to provide placements or practicum opportunities to students undergoing training in vocational, under-graduate and post-graduate interpreting programmes. Knowledge transfer and mentoring of 'in-coming' interpreters, some of whom also found regular employment with TALS, are aligned to TALS' stated aims of improving interpreter performance and service provision in general.

\subsection{Length of stay in hospital}

Another metric used in the measurement of healthcare performance is length of stay (LOS), or the number of days that an inpatient spends at a healthcare facility. Table 4 below presents the LOS for LOP patients, as well as readmission rates for congruent groups of patients.

Table 4: Length of stay (LOS) and re-admission rates amongst patients from a non-English-speaking country of birth (NES COB) and from an Englishspeaking country of birth (ES COB).

\begin{tabular}{lll}
\hline & 2007 & $2015 / 16$ \\
\hline Total no. of patient occasions of service (OOS) & 233,839 & 286,647 \\
\hline No. and \% of service requests for an interpreter & $\begin{array}{l}17,000 \\
(7.3 \%)\end{array}$ & $\begin{array}{l}(\text { est.) } \\
(18.8 \%)\end{array}$ \\
\hline Ave. length of stay (LOS) in days for LEP patients & 8.8 days & 6.3 days \\
\hline $\begin{array}{l}\text { LOS gap between LEP and English-speaking } \\
\text { patients }\end{array}$ & 2.7 & 2.0 \\
\hline Gap in re-admission rates: NES COB vs. ES COB & $1.80 \%$ & $0.10 \%$ \\
\hline
\end{tabular}

Table 4 above shows the length of stay (LOS) in days for limited English proficiency (LEP) patients. LEP patients are defined as those patients whose English proficiency does not enable them to communicate directly with a healthcare worker. In 2007, a substantial proportion of LEP patients were not provided with interpreting services, due to problems in the identification of language barriers and in the booking of interpreter services, as discussed above. LEP patients are widely reported to have a higher LOS compared to English-speaking (ES) patients (Fagan et al., 2003; Borghans et al., 2008; McCarthy et al., 2011). In 2007, the LOS for LEP patients was 8.8 days, while 
by 2015/2016 this gap had dropped to 6.3 days. The drop in LOS for LEP can be attributed to a number of factors, such as improved treatments and advances in home-care services. However, the increase in interpreting services and their reach to a much greater proportion of the LEP patient population is a factor that can also account for a drop in their LOS. Patient-healthcare specialist communication in the elicitation of symptoms and discussion of treatment options is greatly advanced through linguistic mediation provided by interpreters. The augmentation of interpreting services has also occurred alongside a reduction in the LOS difference between LEP and ES patients. The former group spent on average 2.0 days longer in hospital than Englishspeaking patients in 2015/2016 compared to 2.7 days longer in 2007. Lastly, re-admission rates are presented above, which show a substantial reduction in the difference between re-admission rates for patients with a non-Englishspeaking country of birth (NES COB) and patients with an English-speaking country of birth (ES COB). In 2007 this former group had a readmission rate that was $1.80 \%$ higher than that of the latter group. By 2016/2016, this difference had been almost entirely removed with the former group recording a higher re-admission rate of only $0.10 \%$.

\subsection{Relating data on patients' country of birth (COB) to the notion of limited English proficiency (LEP)}

The metric used in this last mentioned set of statistics, country of birth (COB), is a commonly-used one to describe the national or ethnic as well as likely linguistic background of patients. This is, in many ways, an imprecise means to ascertain patients' linguistic profiles, as a demographic detail such as country of birth need not be indicative of English proficiency and whether this is functionally limited or not to require the services of an interpreter. This section examines demographic data on $\mathrm{COB}$ and calculates how people with LEP can be identified quantitatively as sub-group of those whose COB is a predominantly non-English speaking one. ${ }^{\mathrm{v}}$

To locate LEP residents as a sub-group of residents with NES COB, we firstly refer to 2011 census data relating to the two municipal areas within which most $\mathrm{NH}$ healthcare facilities are located, and examine figures on the (self-)reported English language level of residents. These are discussed with a view to gaining a closer estimation of the number of people within NH's catchment area whose English language level is likely to be 'limited', i.e. their proficiency is of a level that does not enable them to interact at a functional level with English-speaking healthcare specialists, so that interpreting services are required. Further, we examine features of the demographic profile of $\mathrm{NH}$ patients themselves to see how these appear to be congruent to those of residents in the two municipalities most proximate to $\mathrm{NH}$.

The two municipal areas in which most $\mathrm{NH}$ healthcare facilities are located in are the City of Whittlesea (2011 total pop. 154,877) and City of Hume (2011 total pop. 167,560). Data collected from census collections in Australia includes responses to questions not only on the country of birth of residents and the language that they speak at home, but also their proficiency level in English, with four selections from which residents choose one: "very

\footnotetext{
${ }^{v}$ Those LEP residents who were born in a predominantly English-speaking country and who returned to their parents' $\mathrm{COB}$ or re-migrated to other NES countries resulting in a limited capacity to acquire English are a very small group. They are not included in statistical data but their exclusion is not likely to have a distorting effect on the overall calculation of LEP residents.
} 
well", "well", "not well" or "not at all". These data, rather than country of birth and language spoken at home are the most relevant data in estimating the number or percentage of local residents who are LEP, i.e. their self-reported English language level indicates that they are unable to functionally communicate in English in healthcare settings.

Data from the municipality of Whittlesea show that $47 \%$ speak a language other than English (LOTE) at home. Amongst those who speak a LOTE at home, those who claim to speak English 'very well' or 'well' account for 35\% while the remaining 12\% speak it 'not well', 'not at all', or provide no response, 'not stated' (Profile.id 2013a). For the municipality of Hume, the equivalent figures are $46 \%$ speaking a LOTE at home, $33 \%$ speaking English 'very well' or 'well', and 13\% with the responses 'not well', 'not at all' and 'not stated' (Profile.id, 2013b). Table 5 below contains these data and comparative data for Greater Melbourne and Australia.

Table 5: Residents' reported language used at home and proficiency level in English, and total overseas-born population

\begin{tabular}{|c|c|c|c|c|c|c|}
\hline & \multicolumn{2}{|c|}{ City of Whittlesea } & \multicolumn{2}{|c|}{ City of Hume } & \multirow{2}{*}{$\begin{array}{l}\text { Greater } \\
\text { Melb. } \\
\%\end{array}$} & \multirow{2}{*}{$\begin{array}{l}\text { Australia } \\
\%\end{array}$} \\
\hline English proficiency & No. & $\%$ & No. & $\%$ & & \\
\hline $\begin{array}{l}\text { Speaks English only } \\
\text { at home }\end{array}$ & 82,659 & 53.4 & 90,837 & 54.2 & 66.3 & 76.8 \\
\hline $\begin{array}{l}\text { Speaks a LOTE at } \\
\text { home and English } \\
\text { very well or well }\end{array}$ & 54,255 & 35.0 & 55,556 & 33.2 & 24.0 & 15.2 \\
\hline $\begin{array}{l}\text { Speaks a LOTE at } \\
\text { home, and English } \\
\text { not well or not at all }\end{array}$ & 11,628 & 7.5 & 12,878 & 7.7 & 5.0 & 3.0 \\
\hline Not stated & 6,335 & 4.1 & 8,288 & 4.9 & 4.6 & 5.0 \\
\hline Total population & 154,877 & 100.0 & 167,559 & 100.0 & 100.0 & 100.0 \\
\hline Total overseas born & 51,966 & 33.6 & 53,906 & 32.2 & 31.4 & 30.7 \\
\hline $\begin{array}{l}\text { Born in NES- } \\
\text { countries }\end{array}$ & 46,712 & 30.2 & 46,742 & 27.9 & 24.2 & 21.0 \\
\hline
\end{tabular}

We now make here an estimate of the percentage of those residents in Whittlesea and Hume whose proficiency in English is strongly indicative of them being LEP residents, and therefore LEP patients of NH. We include all those residents who speak a LOTE at home and who reported that they spoke English 'not well' or 'not at all', i.e. 7.5\% for Whittlesea and 7.7\% for Hume. We estimate that not all, but approximately three-quarters of those who provided no information on the language that they speak at home, i.e. the "not stated' response', are LEP residents. This increases the percentages to $10.5 \%$ for Whittlesea and $11.4 \%$ for Hume. Further, we estimate that one third of those who report that they speak English 'well' or 'very well' are also LEP residents ${ }^{\mathrm{vi}}$. In other words, although residents may consider that they function 'well' in English, in situations in which they are required to understand and provide detailed and sometimes complex information on their state of health,

\footnotetext{
${ }^{\mathrm{vi}}$ Although the Australian census forms provide four gradings for residents to describe their level of English proficiency, reports released by the Australian Bureau of Statistics group the upper two gradings ('very well' and 'well') together as one category and the lower two gradings ('not well' and 'not at all') together as one category. It is not possible to obtain data that distinguish the two gradings 'very well' and 'well' from each other.
} 
their level of English proficiency may still not enable them to do this. It is also likely that some residents overstate rather than understate their proficiency level in English. For example, in a sample of 354 Hispanic-origin patients in the US (Zun et al., 2004, p. 42) 105 identified themselves as "self-proclaimed English speakers". Zun et al. (2004, p. 42) report "a significant difference between patients' tested level of English competency and the physicians' and nurses' assessment of the patients' language competency", adding that "a significant number of patients who report English proficiency have an inadequate level of comprehension". The same authors recommend the "liberal use of interpreters" where healthcare workers have any doubt about language ability. Returning to the percentages from the $\mathrm{NH}$ local government areas, with all groups added together, including a third of those who list that they speak English 'well' or 'very well', this brings the total percentages of LEP residents in these two municipalities to $22.1 \%$ for Whittlesea and $22.5 \%$ for Hume. Other municipalities in NH's catchment areas such as Darebin, Moreland have similar percentages of LOTE-speakers and LEP residents, while further municipalities such as Banyule and Nillumbik have a lower percentage of LEP residents. We therefore estimate that around $20-21 \%$ of the residents in NH's total catchment area have LEP.

As shown above in Table 4, 18.8\% of all OOS at NH were interpretermediated. This suggests that TALS is approaching a level of service provision that is 'comprehensive', i.e. current service provision is only approx. two percentage points lower than the percentage of LEP residents in the areas that NH serves; TALS appears close to providing full coverage of services to those LEP patients who need them. In order to substantiate this claim, we need to ensure that the demographic profile of $\mathrm{NH}$ patients is congruent to the demographic profile of LEP residents in NH's catchment area. Table 6 below shows figures on the number and percentage of OOSs for patients born in NES countries.

Table 6. Number and Occasions of Service for patients born in non-English speaking countries

\begin{tabular}{lll}
\hline & 2007 & $2015 / 16$ \\
\hline Total no. of patient occasions of service (OOS) & 233,839 & 286,647 \\
\hline $\begin{array}{l}\text { No. }+\% \text { of OOSs for patients born in NES } \\
\text { countries }\end{array}$ & $\begin{array}{l}100,133 \\
(43 \%)\end{array}$ & $\begin{array}{l}128,779 \\
(45 \%)\end{array}$ \\
\hline
\end{tabular}

What we see from Table 6 above is that NH patients born in NES countries (non-English speaking countries in which English is not widely used) account for $43 \%$ of NH's OOSs (occasions of service). Table 5 above shows that the percentage of residents born in NES countries in Whittlesea and Hume is not as high: $30.2 \%$ and $27.9 \%$. This shows that residents born in NES countries are disproportionately more likely to be recipients of NH's services - up to 15 percentage points more likely. We do not have direct evidence to account for this higher representation of patients born in NES countries, but other studies from Western countries with large immigrant populations report that those born in other countries often have a higher incidence of use of hospital healthcare services, e.g. Hargreaves et al. (2006), Denktaş et al. (2009), Eziefula and Brown (2010). Further, hospitals rather than GP clinics are sometimes the first service that some immigrant groups use, even for less serious ailments or conditions, (cf. Mahmoud \& Hou, 2012). It is likely that NH's patient population consists overwhelmingly of residents 
that live in areas proximate to it - the $\mathrm{NH}$ 'catchment area'. On the basis of congruent studies, we contend that residents who are born in NES countries (with those who are LEP a sub-set of these) are more likely to use NH services with a higher level of frequency than patients born in Australia or other predominantly English-speaking countries.

This brings us back to consider the NH data and our initial suppositions. We have shown above that the number of overseas-born residents, the number of residents born in NES-countries and those residents who speak a LOTE at home are not all, by these definitions alone, LEP residents. Instead, LEP residents are a proportional sub-set of these bigger groups. It also follows that a higher than local-average percentage of patients who were born in NEScountries (higher than the percentage in the catchment municipalities) will mean that the percentage of patients who are actually LEP will be higher than the average percentage of residents in the local areas that are LEP. LEPpatients appear to more frequently require medical services than Englishspeaking patients. We have estimated the percentage of LEP residents to be around $20 \%-21 \%$ in the catchment municipalities. We estimate that around a third of the 'additional up to 15\%' of patients born in NES countries, (i.e. a further five percentage points) are LEP patients. This means that the percentage of all patients who are LEP patients who require interpreting services is close to $25 \%$. Thus, while TALS has been able to greatly increase and improve service provision to $18.8 \%$ of all OOSs, the target of 'comprehensive' coverage has still not quite been achieved.

\subsection{Linguistic mediation performed by in-house, non-interpreting staff - policy guidelines}

The above sections present data and viewpoints on the activities of TALS staff members. While the vast bulk of inter-lingual transfer is performed by TALS staff members, the linguistic profiles of other staff members also need to be considered, particularly with reference to studies of inter-lingual transfer in hospitals that show that bilingual staff members may commonly volunteer or be requested to 'translate' (Pöchhacker \& Kadric, 1999; Bischoff \& Loutan, 2004; Meyer, 2012). In the instance of NH staff, some may volunteer or feel compelled to interpret for others, regardless of their linguistic proficiency.

A large number of $\mathrm{NH}$ employees are bi- or multilingual and proficiency in languages other than English is distinguished as a preferred attribute of potential employees in advertisements. The NH Transcultural Healthcare Policy from 2008 advocates the recruitment and selection of staff who reflect the diversity, including linguistic diversity of the community that it serves. According to the 2017 Diversity Survey conducted as part of the 2017-2019 Cultural Responsiveness Plan, 32\% of NH employees speak a language other than English at home. This raises the question of those employees who have proficiency in a LOTE and their ability and preparedness to engage with patients either as interlocutors communicating with them monolingually in LOTE, or as linguistic mediators interpreting for CALD patients and other English-speaking staff. Northern Health $(2012$, p. 3) has the following guidelines for staff that formalise protocols of LOTE use with patients, but which does not include interpreting, unless they have the relevant accreditation:

Bilingual clinical staff can use their languages skills in the context of their own work if they feel comfortable that they can provide quality care to patients. (Northern Health, 2016, p. 4) 
The guidelines are nuanced so that those who use their LOTE are not compelled to use it in situations when they feel that their proficiency level does not enable them to do what they need to:

Bilingual staff have the right to access interpreters for the language that they speak if they do not feel comfortable using their own language skills. (Northern Health, 2016, p. 4)

The instances in which such staff do interpret are the exception rather than the rule, and there is a procedural requirement to declare that information gained from such an interaction was not gained via an in-house staff interpreter. Financial recognition to those staff (outside TALS) with an interpreter accreditation who employ their interpreting skills in their work is also awarded (cf. Section 3 and the Language Availability Performance Allowance for other public servants):

NAATI qualified staff members can interpret for their own patients; when they do so instead of booking an interpreter, they will receive a pre-determined additional payment for the day, even if they interpret for more patients within the same day. (Northern Health, 2016, p.4)

Apart from the content of this cited document, its title and authorship are also of note: Northern Health Transcultural Health Care Policy produced by Northern Health itself. This document is a 'how-to' text that sets out the actual operationalisation of T\&I services, i.e. it describes CALD patients' profiles, TALS staff duties, non-TALS staff protocols for contact with CALD patients and brings these together to specify how inter-lingual transfer, transcultural expertise and the provision of patient care are operationalised. It is a document that is very much a response to the 'top-down' directives made from a variety of policy areas. It is also an 'at the coalface' document in that it specifies the logistic procedures that a policy can state in only a general directional sense.

\section{Conclusion}

This paper had policy as its starting point. We locate documents reflective of public policy - legislation, charters, frameworks and other authoritative guidelines - including those relating to healthcare as one of the prominent areas of public policy and relevant to our examination of health outcomes. Both social policy and health policy coincide in their advocacy of language services. The former does so on the grounds of access and equity for all Australian residents, regardless of their linguistic proficiency in English. The latter does so to enable efficient and accurate patient-healthcare professional communication, which in turn serves to optimise healthcare outcomes for patients. Macro-level directives such as these can be the basis for the development of local-level guidelines that set out the operationalisation of a policy in a specific environment (Horvat, 2017). It is important that there are macro-level directives that specify these policy directions, as without such directives, there are fewer incentives to develop local-level guidelines and a greater risk that such guidelines may be disregarded.

The development of local-level guidelines relating to the provision of services referred to this in this study, the Northern Health Cultural Responsiveness Plan, foresaw the following; a streamlining of interpreter booking services together with the dissemination of information on 
communicating with LEP patients and how to discern need for interpreting services; PD training for new and existing staff on transcultural health; an increase in employment of in-house interpreters as a means to ensure consistent standards of service delivery but with unknown budgetary consequences.

There are positive health outcomes for LEP patients that coincide and correlate with the restructuring and augmentation of interpreting services. These are a $28 \%$ decrease in length of stay (LOS) from 8.8 to 6.3 days in hospital, and a reduction in the difference between the re-admission rates for patients born in non-English-speaking countries compared to those born in English-speaking countries from $1.80 \%$ to $0.10 \%$. We argue that these substantial health outcomes for LEP patients are partly attributable to the augmentation of interpreting and other related services. The number of service requests for interpreters increased $317 \%$ from approx. 17,000 to 53,822 over an eight-year period, and the percentage of all occasions of service (OOS) that were interpreter-mediated increased from $7.3 \%$ to $18.8 \%$. A larger part of these are serviced by in-house interpreters who cover $60 \%$ of demand.

An augmentation of in-house interpreting staff has resulted in these becoming a lower-cost factor than externally-contracted interpreters: in-house interpreters are $\mathrm{A} \$ 22.47$ cheaper per patient OOS. The ability to provide training to new and existing staff has been instrumental in providing awareness of the communication (and other) needs of culturally and linguistic diverse groups of patients, and of the need to reliably and effectively communicate with all patients including the need for interpreters for those patients whose English proficiency level does not allow them to communicate in this language with healthcare specialists.

An adequate allocation of interpreting services to LEP patients is possible only where all healthcare staff are aware of the communication needs of all parties in healthcare interactions. This is not easy to achieve, as there can be reluctance on the part of others to acknowledge an incapacity to communicate adequately with patients, to take the step of requesting an interpreter, and in factoring extra time for an OOS that is consecutively interpreted. As reported by one in-house interpreter in section 5.2 above, “... there are people who engage better than others. And typically medical people are the slowest to take that kind of stuff [using interpreting services] up and are the hardest to get to." There needs to be not only policy and organisational directives for particular practices to be known about and applied. There also need to be human resources to support and operationalise these practices, and to demonstrate in a real and immediate sense how these practices can be implemented, how services can be used, and to point to advantageous outcomes, not only for patients but for all participants in healthcare interactions, including healthcare professionals, patients' family members and others.

From the field of Policy Studies we learn that policy is not a single event, but a process that encompasses the activities of multiple stakeholders who may act in concert with each other or not. There is usually not one decisionmaker but multiple actors in the policy development process, while the notion of what an 'issue' and how it is best addressed, with which means and implemented by whom, are all variables that are subject to evaluation and reevaluation. The same applies to those implementing policy at a lower level. An important aspect of policy, its evaluation, the scoping of major change or minor modification, and the development of further iterations of the same policy or shift to a different policy is the measurement or quantification of current policy directives. This paper has taken the example of policy content 
and its implementation in the health sector to demonstrate that augmented interpreter services have positive outcomes on patient health, and that these positive outcomes are substantial and the cost savings from such outcomes outweigh the cost outlay for an increase in in-house interpreter staffing. We have shown that an augmented level of service has advantageous outcomes, but suggest that service provision here is not yet comprehensive in reaching the total number of all LEP patients. It is likely that service provision that goes beyond the current level of $18.8 \%$ of all patient OOS to approach a proportion of $25 \%$ of all patients will deliver still further, positive outcomes for LEP patients in terms of LOS and re-admission rates.

\section{References}

All of Us, Victoria's Multicultural Policy, (2010). Retrieved from http://www. multicultural.vic.gov.au/images/stories/pdf/MulticulturalPolicy09-res.pdf

Anderson, J. (1984). Public policy making - an introduction: San Diego: Harcourt Brace.

Angelelli, C. (2004). Medical interpreting and cross-cultural communication. Cambridge,UK: Cambridge University Press.

Australian Commission on Safety and Quality in Healthcare (2016). Australian Charter of Healthcare Rights in Victoria. Retrieved from https://www2.health. vic.gov.au/Api/downloadmedia/\%7BDE714241-FC53-440F-83CA-4C53D44D0 FA1\%7D.

Australian Charter of Healthcare Rights (2008). Retrieved from http://www. safetyandquality.gov.au/national-priorities/charter-of-healthcare-rights/

Bacchi, C. (2009). Analysing policy: what's the problem represented to be? (1st ed) Frenchs Forest, NSW: Pearson.

Bischoff, A. \& Loutan, L. (2004). Interpreting in Swiss hospitals. Interpreting 6(2), 181-204.

Borghans, I., Heijink, R., Kool, T., Lagoe, R.J \& Westert, G. (2008). Benchmarking and reducing length of stay in Dutch hospitals. BMC health services research $8(1), 220$

Buse, K., Mays N., \& Walt, G. (2005). Making health policy (Understanding public health). Maidenhead, Berkshire: Open University Press.

Denktaş, S., Koopmans, G., Birnie, E., Foets, M. \& Bonsel, G. (2009). Ethnic background and differences in health care use: a national cross-sectional study of native Dutch and immigrant elderly in the Netherlands. International journal for equity in health, $8(1), 1$.

Department of Education and Early Childhood Development (2009). Victorian education for global and multicultural citizenship 2009-2013. Retrieved from http://www.education.vic.gov.au/Documents/school/teachers/health/multiculteds trat.pdf.

Department of Health and Human Services, Victorian Government (2017). Language services policy and guidelines. Retrieved from https://dhhs.vic.gov.au/ publications/ language-services-policy-and-guidelines

Department of Health, Victorian Government (2009). Victorian Department of Health's Cultural Responsiveness Framework. Accessed 31 January 2016. Retrieved from http://www.health.vic.gov.au/_data/assets/pdf_file/0008/ 381068/cultural_responsiveness.pdf.

Department of Health, Western Australia (n.d.) Definition and counting rules for occasion of service. Retrieved from http://www.health.wa.gov.au/circularsnew/ attachments/295.pdf.

Department of Premier and Cabinet, State Government of Victoria (2005). A vision for Victoria to 2010 and beyond: growing Victoria together. Retrieved from http://trove.nla.gov.au/version/166828568 
Dye, T. R. (1972). Policy analysis and political science: Some problems at the interface. Policy Studies Journal, 1(2), 103-107.

Eziefula, C, \& Brown, M. (2010). The health of recent migrants from resource-poor countries. Medicine, 38(1), 60-65.

Fagan, M., Diaz, J., Reinert, S., Sciamanna, Ch. \& Fagan, D. (2003). Impact of interpretation method on clinic visit length. Journal of General Internal Medicine. 18(8), 634-638.

Garrett, P. (2009). Healthcare interpreter policy: Policy determinants and current issues in the Australian context. International Journal for Translation \& Interpreting Research, 1(2). 44-54

Hargreaves, S., Friedland, J., Gothard, P., Saxena, S., Millington, H., Eliahoo, J., Le Feuvre, P., Holmes, A. (2006). Impact on and use of health services by international migrants: questionnaire survey of inner city London A\&E attenders. BMC Health Services Research, 6: 1.

Hlavac, J. (2016). Interpreter credentialing, testing and training in Australia: past, contemporary and future directions. FITISPos International Journal. Public Service Interpreting and Translation. 3. 59-81.

Hlavac, J., Gentile, A., Orlando, A., Zucchi, E. \& Pappas, A. (forthcoming) Translation as a sub-set of public and social policy and a consequence of multiculturalism: The provision of translation and interpreting services in Australia. International Journal of the Sociology of Language.

Hof, M. R. (2013). The death of healthcare interpreting in the Netherlands. Aiic.Net. October 10, 2013. Retrieved from http://aiic.net/p/6612.

Horvat, L. (2017). Toward a new approach to culturally and linguistically responsive health care: a case study of developments in Victoria, Australia. In E. Jacobs \& L. Diamond (Eds.) Providing health care in the context of language barriers. (pp. 186-199). Briston: Multilingual Matters. 186-199

Jenkins, W. (1978). Policy analysis : a political and organisational perspective. London: M. Robertson.

Johnstone, M.-J. \& Kanitsaki, O. (2007a). Health care provider and consumer understandings of cultural safety and cultural competency in health care: an Australian study. Journal of Cultural Diversity. 14, 96-105.

Johnstone, M.-J. \& Kanitsaki, O. (2007b). An exploration of the notion and nature of the construct of cultural safety and its applicability to the Australian health care context. Journal of Transcultural Nursing. 18, 247-256.

Lindholm, M., Hargraves, L., Ferguson, W. \& Reed. G. (2012). Professional language interpretation and inpatient length of stay and readmission rates. Journal of General Internal Medicine 27(10), 1294-1299.

Lo Bianco, J. (1987). National policy on languages. Canberra: Australian Government Publishing Service.

Lowi, Th. \& Ginsberg, B. (1996). American government: freedom and power. New York: Norton.

Mahmoud, I, \& Hou, X.-Y. (2012) Immigrants and the utilization of hospital emergency departments. World journal of emergency medicine 3(4), 245.

McCarthy, M. L., Ding, R., Pines, J. \& Zeger, S. (2011) Comparison of methods for measuring crowding and its effects on length of stay in the emergency department. Academic Emergency Medicine 18(12), 1269-1277.

Meyer, B. (2004). Ad hoc interpreting for partially language-proficient patients. Participation in multilingual constellations. In C. Baraldi \& L. Gavioli (Eds.) Coordinating participation in dialogue interpreting. (99-113). Amsterdam/ Philadelphia: John Benjamins.

Northern Health (2012). The 2013-2015 Northern Health Cultural Responsiveness Plan. Retrieved from http://www.nh.org.au/userfiles/files/TALS/2013-2015\% 20NH\% 20Cultural\%20Responsiveness\%20Framework\%20\%20Plan.pdf.

Northern Health (2016). Transcultural Health Care Policy. Melbourne: Northern Health.

Ozolins, U. (2010). Factors that determine the provision of Public Service Interpreting: comparative perspectives on government motivation and language 
service implementation. Journal of Specialised Translation 14. 194-215. Retrieved from http://www.jostrans.org/issue14/art_ozolins.php

Pöchhacker, F. \& Kadric, M. (1999). The hospital cleaner as healthcare interpreter: a case study. The Translator 5(2), 161-178.

Profile.id (2013a). City of Whittlesea. Proficiency in English. Retrieved from http://profile.id.com.au/whittlesea/speaks-english

Profile.id (2013b). City of Hume. Proficiency in English. Retrieved from http://profile.id.com.au/hume/speaks-english

Sabatier, P. (2007). The need for better theories. In P. Sabatier (Ed.) Theories of the policy process (pp. 3-17). Boulder, CO: Westview Press.

State Government of Victoria. (2006) A fairer Victoria. Progress and next steps. Retrieved from http://www.communitylaw.org.au/clc_loddoncampaspe/ cb_ pages/images/A_Fairer_Victoria_2006.pdf

Zun, L. S., Sadoun, T. \& Downey L. (2004) English language competency of selfdeclared English-speaking Hispanic patients. Annals of Emergency Medicine. 44(4), S42-43.

Acts

Charter of Human Rights and Responsibilities Act [Victoria] 2006. Retrieved from http:/www.legislation.vic.gov.au/Domino/Web Notes/LDMS/PubStatbook.nsf/e dfb620cf7503d1aca256da4001b08af/54D73763EF9DCA36CA2571B6002428B 0/\$FILE/06-043a.pdf

Health Services Act [Victoria] 1988. Retrieved from www.legislation.vic.gov.au/ Domino/Web...nsf/.../88-49aa133\%20authorised.pdf

Human Rights and Equal Opportunity Act, 1986 Retrieved from https://www.legislation.gov.au/Series/C2004A03366

Mental Health Act [Victoria], 1986 Retrieved from www.legislation.vic.gov.au/ Domino/Web_Notes/LDMS/...Store/.../86-59a098.pdf

Multicultural Victoria Act, 2004. Retrieved from http://www.multicultural.vic.gov.au/ images/stories/pdf/mav\%202004.pdf

Racial And Religious Tolerance Act [Victoria], 2001 Retrieved from http://www.austlii.edu.au/au/legis/vic/consol_act/rarta2001265 


\section{Appendix}

Group 1 informants

For TALS staff and language-services contracted interpreters

Interview questions for semi-structured interview. Further questions based on participants' individual responses may be asked.

1. How long have you worked at TALS, or worked in some capacity with TALS staff?

2. Describe TALS as an organisational unit. Describe also how TALS works.

3. What do you understand cultural competence to be?

4. Patient-centred care is a focus of contemporary healthcare providers. Tell us about how patient-centred care is provided for CALD patients?

5. What do you know about the restructuring of language services in the health care sector and the establishment of TALS in 2007?

6. How were other areas of Northern Health serviced by interpreting and trans-lingual services before the re-establishment of TALS?

7. What is your perception of how other areas of NH view TALS?

8. How is this manifested in an operational sense?

9. How do NH colleagues work with CALD patients who may need interpreting and other trans-lingual services?

10. Comparing other healthcare providers known to you, how is TALS similar to them and how is TALS different to them?

11. What future challenges is TALS likely to encounter?

12. Do you have any further comments to make about the working of TALS?

Group 2 informants

For NH healthcare managers whose management areas include contact with TALS

Interview questions for semi-structured interview. Further questions based on participants' individual responses may be asked.

1. Tell me something about the areas that you are responsible for.

2. What needs has your area had to work with and treat CALD patients?

3. What do you understand cultural competence to be?

4. Patient-centred care is a focus of contemporary healthcare providers. Tell us about how patient-centred care is provided for CALD patients?

5. How were services for CALD patients provided before the reestablishment of TALS? 
6. What do you know about the restructuring of language services in the health care sector and the establishment of TALS in 2007?

7. Did you have an active role in the restructuring and re-establishment of TALS? If yes, please give details of this. If no, could you bear any influence on the way TALS would be re-established?

8. How do you view TALS now?

9. How do TALS staff work with other parts of NH and how do you think TALS staff view other parts of NH?

10. Do you know about the provision of language services at other healthcare providers and can you compare them to TALS?

11. What organisational challenges is TALS likely to encounter in the future?

12. Do you have any further comments to make about the working of TALS?

\section{Group 3 informants}

For T\&I sector stakeholders who have/had contact with TALS and NH.

1. Interview questions for semi-structured interview. Further questions based on participants' individual responses may be asked.

2. Tell me something about the areas that you work in?

3. Tell me about how you work with healthcare providers and the provision of language services in the healthcare sector, which is the largest volume area of interpreting in this country?

4. Tell me about how interpreting in the healthcare sector has been provided now and over the last one to two decades.

5. What do you know about the restructuring of language services in the health care sector and the establishment of TALS in 2007?

6. What is the role of public healthcare providers in advancing the translation and interpreting sector, and in improving the quality of training for interpreters?

7. What do you understand cultural competence to be?

8. Patient-centred care is a focus of contemporary healthcare providers. Tell us about how patient-centred care is provided for CALD patients?

9. Does TALS contribute to the T\&I sector? If yes, how? If not, why not?

10. Tell me about your views on how the quality of language services can be improved, for the healthcare sector, and in other sectors.

11. How should the trainers of T\&I students work with the T\&I sector? What is the role of healthcare providers in this?

12. In terms of policy or legislation at federal or state level, are there changes that need to be made for the T\&I sector?

13. What challenges is the T\&I sector likely to encounter in the future?

14. Do you have any further comments to make about the working of TALS? 